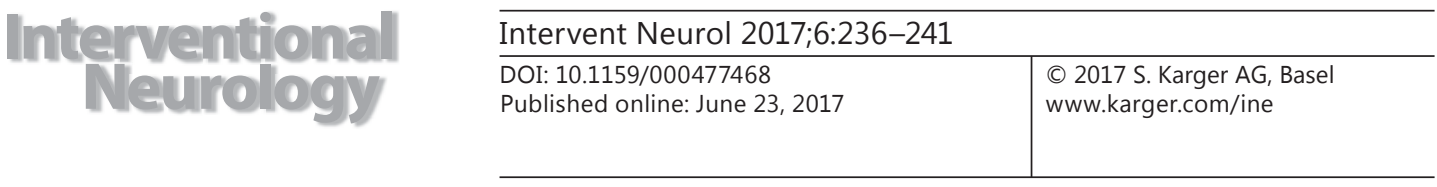

\title{
Trends in Endovascular Treatment of Aneurysmal Subarachnoid Hemorrhages
}

\author{
Tapan Mehta $^{a} \quad$ Neil Datta $^{a}$ Smit Patel $^{b} \quad$ Kathan Mehta $^{b}$ \\ Mohammed Hussain $^{c}$ Inaam Kureshi ${ }^{d}$ Martin Ollenschleger ${ }^{c}$ \\ Amre Nouhe \\ ${ }^{a}$ Department of Neurology, University of Connecticut Health, Farmington, CT, b University \\ of Pittsburgh, Pittsburgh, PA, and Departments of ' Interventional Neuroradiology, \\ d Neurosurgery, and e Neurology, Hartford Hospital, Hartford, CT, USA
}

\section{Keywords}

Endovascular therapy · Subarachnoid hemorrhage $\cdot$ Aneurysm · Vasospasm · Mortality

\begin{abstract}
Introduction: Aneurysmal subarachnoid hemorrhage (aSAH) accounts for $5 \%$ of all strokes; 30-day mortality is as high as $40 \%$. We sought to evaluate outcomes of aSAH patients treated 2004-2014 by endovascular therapy (EVT), to demonstrate associated trends, and to evaluate angioplasty use for aSAH-related cerebral vasospasm. Methods: The Nationwide Inpatient Sample (NIS) database 2004-2014 was used to derive a study cohort using ICD-9 codes. Survey procedures were used to adjust for stratified cluster design of NIS. NIS trend weights were used to generate national estimates. Mortality during hospitalization and use of angioplasty for aSAH-induced cerebral vasospasm trends were evaluated with multivariate regression analysis. Results: We identified $n=10,822$ (weighted $n=52,062$ ) EVT-treated aSAH hospitalizations. Increasing years independently predicted decreased mortality (odds ratio [OR] 0.926, $95 \%$ confidence interval [CI] $0.905-0.948, p<0.0001$ ), decreased utilization of angioplasty (age $\geq 50$ years [OR $0.916,95 \%$ CI $0.867-0.968, p=0.0019$ ] and age $<50$ years [OR $0.922,95 \%$ CI 0.879-0.967, $p=0.0009]$ ) after controlling for increasing age, Charlson comorbidity index, and external ventricular drain placement. Angioplasty rates were higher in age $<50$ years compared to age $\geq 50$ years ( 5 vs. $3.63 \%, p<0.001$ ). Conclusion: It is notable that EVT for aSAH management will be an integral and increasingly useful tool for initial aneurysm management. Advances in procedural techniques, operator experience, and periprocedural management could be significant contributors of decreasing mortality and reducing the need for angioplasty for cerebral vasospasm in patients admitted with aSAH.

(c) 2017 S. Karger AG, Basel
\end{abstract}

Tapan Mehta, MD, MPH

Department of Neurology, University of Connecticut Health/Hartford Hospital

80 Seymour Street

Hartford, CT 06102 (USA)

E-Mail mehta230@umn.edu or tapanmehta14@gmail.com 


\section{Introduction}

Aneurysmal subarachnoid hemorrhage (aSAH) accounts for $5 \%$ of all strokes and affects up to 22 per 100,000 persons per year worldwide. The 30-day morbidity and mortality have been reported to be as high as 50 and $40 \%$, respectively [1,2]. Emergent treatment of aSAH is primarily focused on securing the ruptured aneurysm by surgical or endovascular means. At one point, microsurgical aneurysmal clipping was the standard of care [3]. With the advent of endovascular therapy (EVT) reaching parity by 2005 in the US, craniotomy and microsurgical clipping has declined [4]. Early on, EVT demonstrated its efficacy in reducing aneurysmal rebleeding post aSAH [5-7]. In the International Subarachnoid Aneurysm Trials (ISAT), 1-year outcomes for EVT fared better over clipping considering morbidity, mortality, and seizure rate $[8,9]$.

Management of aSAH has advanced significantly since EVT for intracranial aneurysms started more than 20 years ago [10]. This reflects in part the development of better materials, devices, operator skill, and improved neurocritical care management. Rincon et al. [11] evaluated epidemiology of nontraumatic subarachnoid hemorrhage using the National Hospital Discharge Survey (NHDS) database from 1979 to 2008, which showed a decrease in overall mortality; however, this study did not specifically evaluate aSAH treated with EVT. We sought to evaluate outcomes of aSAH treated from 2004 to 2014 by EVT and demonstrate the associated trends. We also aimed to evaluate angioplasty use for aSAH-related cerebral vasospasm.

\section{Methods}

The study cohort was derived from the Nationwide Inpatient Sample (NIS) database between 2004 and 2014. The NIS is the largest publicly available de-identified all-payer inpatient care database and is part of the Healthcare and Cost Utilization Project (HCUP). The NIS contains a sample of $20 \%$ of US hospitals and contains information on approximately 7 million hospitalizations per year. It is published in discharge abstract safeguarding format to de-identify of hospital and patient information.

ICD- 9 codes 430,431 , and 432 in conjunction with ICD-9 procedure code 39.72 (endovascular repair/ embolization of head and neck vessel) were used to identify patients with aSAH treated with EVT (ICD-9 747.81 - cerebral arteriovenous malformation was excluded). Patients requiring external ventricular drain (EVD) and cerebral angioplasty were also identified to stratify higher-severity aSAH. In addition, a separate, but related study was done to evaluate cerebral vasospasm treated with angioplasty, with ICD procedure codes 00.62 and 39.50 used to identify candidate cases.

In both evaluations, comorbidities were controlled using the Charlson comorbidity index. The age of 50 has been demonstrated as a cutoff for differential risk of aSAH cerebral vasospasm [12]. Thus, subgroup analyses were done with the population being divided into ages $<50$ and $\geq 50$ to elucidate differences in angioplasty trends.

Unpaired $t$ test and Mann-Whitney $\mathrm{U}$ test were used to test differences between continuous variables. $\chi^{2}$ test and Fisher exact test were used to test differences between categorical variables. Logistic regression was used for categorical variables controlling for confounder. SAS 9.4 (SAS Institute, Cary, NC, USA) was used for all analysis. Survey procedures were used to adjust for stratified cluster design of NIS. Trend weight provided by NIS was used to generate national estimates.

\section{Results}

We identified $n=10,822$ (weighted $n=52,062$ ) hospitalizations where aSAH was treated endovascularly (Fig. 1). Table 1 shows baseline characteristics of this population. The average age of the study cohort was 54.21 years, with $38.49 \%$ younger than the age of 50 years, and 
Mehta et al.: Trends in Endovascular Treatment of Aneurysmal Subarachnoid Hemorrhages

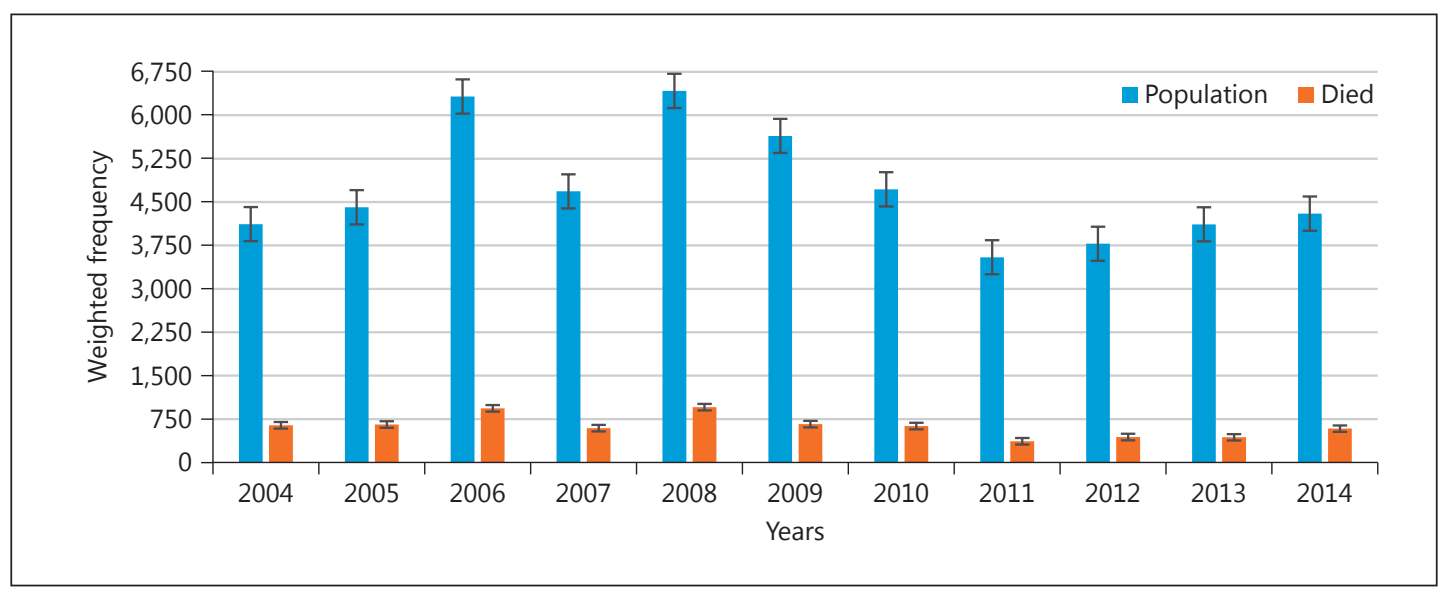

Fig. 1. Trends of population and mortality (weighted $n=52,062$ ).

Table 1. Baseline table ( $n=10,822$, weighted $n=52,062)$

\begin{tabular}{|c|c|c|c|c|c|c|c|c|}
\hline No. & Variables & $\begin{array}{l}\text { Population } \\
(n=10,822, \\
\text { weighted } \\
n=52,062)\end{array}$ & $\begin{array}{l}\text { Standard } \\
\text { error }\end{array}$ & $\begin{array}{l}\text { Age }<50 \\
(n=4,008, \\
\text { weighted } \\
n=19,302)\end{array}$ & $\begin{array}{l}\text { Standard } \\
\text { error }\end{array}$ & $\begin{array}{l}\text { Age } \geq 50 \\
(n=6,814, \\
\text { weighted } \\
n=32,760)\end{array}$ & $\begin{array}{l}\text { Standard } \\
\text { error }\end{array}$ & $\begin{array}{l}\text { Univariate } \\
p \text { value } \\
\text { comparing } \\
\text { age }<50 \text { and } \\
\text { age } \geq 50\end{array}$ \\
\hline 1 & Age $($ mean \pm SEM) & 54.21 & 0.18 & 38.49 & 0.19 & 63.45 & 0.12 & $<0.001$ \\
\hline 2 & Gender, female & 65.63 & 0.50 & 61.51 & 0.77 & 68.10 & 0.59 & $<0.001$ \\
\hline 3 & Charlson index (mean \pm SEM) & 1.75 & 0.016 & 1.56 & 0.02 & 1.86 & 0.02 & $<0.001$ \\
\hline 4 & EVD placement & 9.58 & 0.65 & 8.51 & 0.68 & 10.21 & 0.69 & 0.02 \\
\hline 5 & Angioplasty & 4.14 & 0.26 & 5.00 & 0.41 & 3.63 & 0.28 & $<0.001$ \\
\hline 6 & Died & 13.27 & 0.41 & 8.95 & 0.46 & 15.81 & 0.56 & $<0.001$ \\
\hline 7 & Significant disability & 36.14 & 0.88 & 25.39 & 0.94 & 42.46 & 0.98 & $<0.001$ \\
\hline 8 & $\begin{array}{l}\text { Admissions during weekend } \\
\text { Hospital bed size }\end{array}$ & 26.28 & 0.44 & 26.02 & 0.72 & 26.43 & 0.54 & 0.659 \\
\hline 9 & Small hospital bed size & 3.32 & 0.71 & 3.39 & 0.63 & 3.28 & 0.74 & 0.757 \\
\hline 10 & Medium hospital bed size & 12.12 & 1.57 & 12.50 & 1.60 & 11.89 & 1.53 & 0.367 \\
\hline 11 & Large hospital bed size & 83.78 & 1.75 & 83.35 & 1.77 & 84.10 & 1.72 & 0.244 \\
\hline 12 & Missing & 0.79 & 0.32 & 0.88 & 0.39 & 0.73 & 0.29 & 0.40 \\
\hline
\end{tabular}

All values are in percent (\%) unless otherwise indicated. EVD, external ventricular drain. Significant disability: patients discharged to intermediate care and skilled nursing facility defined by the Nationwide Inpatient Sample (NIS), requiring long-term post-hospitalization care. Definition of hospital bed size based on NIS definition.

female patients accounted for $65.63 \%$. The overall mortality was $13.27 \%$, with a significantly higher mortality rate in age $\geq 50$ years ( 15.81 vs. $8.95 \%, p<0.001)$. The rate of EVD placement was higher in patients $\geq 50$ years ( 10.21 vs. $8.51 \%, p=0.02)$, whereas the rate of angioplasty was higher in patients $\leq 50$ years ( 5.00 vs. $3.63 \%, p<0.001$ ). Overall, $26.28 \%$ admissions occurred during weekends and $83.78 \%$ were in large bed size hospitals (per NIS database definition of large bed size hospitals). Figure 1 demonstrates the mortality odds outcomes trended over time compared to mortality in 2004. Increasing years independently predicted decreased mortality (odds ratio [OR] 0.926, 95\% confidence interval [CI] 0.905-0.948, $p<$ 0.0001) after controlling for age, Charlson index, and EVD placement (Fig. 2). 
Fig. 2. Trends of mortality (final selected model: 0 joinpoints) and predictors of mortality in endovascularly treated aneurysmal subarachnoid hemorrhage (aSAH) patients. APC, annual percent change; EVD, external ventricular drain. * Significantly different from zero at alpha $=0.05$. (c) 2017 S. Karger AG, Basel www.karger.com/ine

Mehta et al.: Trends in Endovascular Treatment of Aneurysmal Subarachnoid Hemorrhages

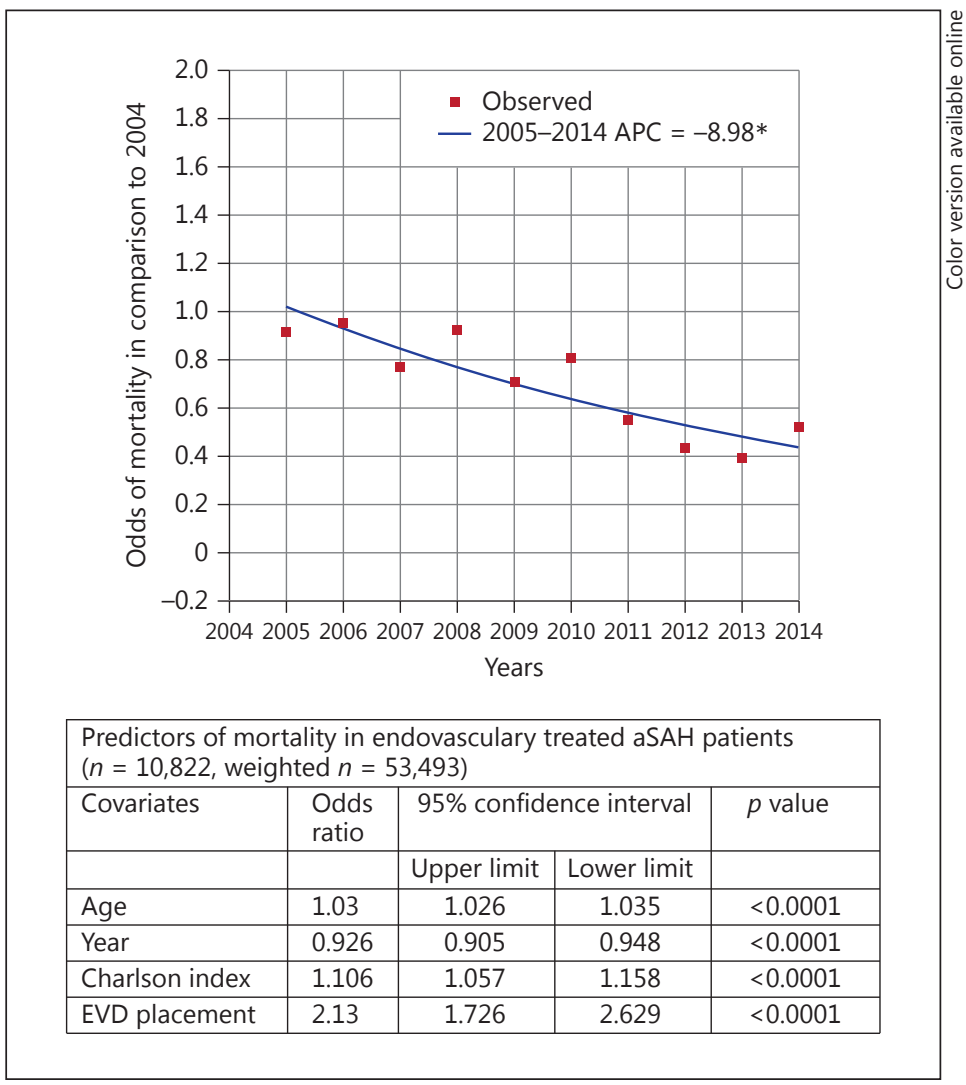

In studying aSAH cerebral vasospasm treated with angioplasty, we found that after 2004 every additional year independently predicted decreased utilization of angioplasty (age $\geq 50$ years [OR $0.916,95 \% \mathrm{CI} 0.867-0.968, p=0.0019$ ] and age $<50$ years [OR 0.922 , 95\% CI 0.879 $0.967, p=0.0009]$ ) after controlling for increasing age, Charlson comorbidity index, and EVD placement. Requirement of EVD placement in the age $<50$ years population also predicted increased utilization of angioplasty (OR 2.023, 95\% CI 1.230-3.326, $p=0.0055$ ) (Table 2).

\section{Discussion}

aSAH bears significant morbidity and mortality risks. EVT is slowly becoming the preferred treatments for aSAH, due to its improved overall outcomes and minimally invasive nature. In general, the few cases wherein aSAH treatment from rupture is being deferred to clipping are due to large or giant aneurysm size, or aneurysmal neck characteristics unfavorable for EVT despite balloon remodeling [13].

Our study cohort had an overall female gender preponderance, as well as higher mortality, comorbidity, disability at discharge, and EVD placement rate within the 50 years and older patient subgroup. In addition, the higher rates of angioplasty for cerebral vasospasm in younger than 50 years patients echo previously published demographic data in an aSAH population [12].

As expected, multivariate models showed that increasing age, Charlson comorbidity index, and requirement of EVD placement were independent predictors of mortality. Although it is already established that with appropriate case selection, EVT could be superior to surgical 
Mehta et al.: Trends in Endovascular Treatment of Aneurysmal Subarachnoid Hemorrhages

Table 2. Predictors of requiring angioplasty in endovascularly treated aneurysmal subarachnoid hemorrhage patients $(n=10,822$, weighted $n=52,062$ )

\begin{tabular}{|c|c|c|c|c|}
\hline \multirow[t]{2}{*}{ Covariate } & \multirow[t]{2}{*}{$\begin{array}{l}\text { Odds } \\
\text { ratio }\end{array}$} & \multicolumn{2}{|c|}{$\begin{array}{l}\text { 95\% confidence } \\
\text { interval }\end{array}$} & \multirow[t]{2}{*}{$p$ value } \\
\hline & & $\begin{array}{l}\text { upper } \\
\text { limit }\end{array}$ & $\begin{array}{l}\text { lower } \\
\text { limit }\end{array}$ & \\
\hline \multicolumn{5}{|l|}{ Age $<50$ years } \\
\hline Age & 1.012 & 0.999 & 1.025 & 0.0655 \\
\hline Year & 0.922 & 0.879 & 0.967 & 0.0009 \\
\hline Charlson index & 1.175 & 1.067 & 1.294 & 0.001 \\
\hline EVD placement & 2.023 & 1.230 & 3.326 & 0.0055 \\
\hline \multicolumn{5}{|l|}{ Age $\geq 50$ years } \\
\hline Age & 0.969 & 0.957 & 0.982 & $<0.0001$ \\
\hline Year & 0.916 & 0.867 & 0.968 & 0.0019 \\
\hline Charlson index & 1.184 & 1.086 & 1.291 & 0.0001 \\
\hline EVD placement & 1.557 & 0.916 & 2.647 & 0.1014 \\
\hline
\end{tabular}

EVD, external ventricular drain.

clipping [9], our study demonstrates an important trend of decreasing mortality. This suggests continuous improvement in outcomes and successful treatment rates of aSAH with EVT as time progressed from 2004 to 2014.

Cerebral vasospasm is another significant complication of aSAH and one of the major determinants of functional outcome. Vasospasm has been implicated in delayed ischemic neurologic deficit in $17-40 \%$ of aSAH patients $[12,14,15]$. Although there has been some controversy with respect to age and aSAH cerebral vasospasm, Kale and colleagues [12] showed that patients under 50 years of age carry an up to 5 -fold increased risk of vasospasm compared with older patients. Our study demonstrated a higher rate of angioplasty utilization ( $5 \%$ [age $<50$ ] vs. 3.63\% [age $\geq 50], p<0.001$ ) in a younger population. Also, requirement of EVD placement was an independent predictor of angioplasty utilization in the age $<50$ years subpopulation. These findings support the hypothesis that younger patients with an overall higher severity of SAH would entail a higher risk of developing cerebral vasospasm

There were notable aspects we could not measure. We could not specifically evaluate trends of intra-arterial calcium channel blocker (CCB) use due to lack of specific ICD-9 procedure coding. One potential reason of the decreasing trend of angioplasty could be the increasing use of intra-arterial CCBs for aSAH-related vasospasm. Intra-arterial CCBs have demonstrated significant reductions in transcranial Doppler velocities, and vessel caliber has been shown to be increased by as much as $44 \%$. Although the role of CCBs in vasospasm is not fully elucidated, in some studies, up to $72 \%$ of patients have had clinical improvement as well [16-18]. Still, it is important to note the decreasing trend of angioplasty in the older than 50 years of age population. Location and size of the aneurysm was not an available metric in the database; thus, it could not be controlled in the multivariate models. A majority of the cases were treated in larger hospitals (83.89\%) in our study cohort. However, neurocritical and periprocedural care was not standardized, as this was a national retrospective study.

\section{Conclusion}

It is notable that EVT for aSAH management will be an integral and increasingly useful tool for initial aneurysm management. Advances in procedural techniques, operator experience, and periprocedural management could be significant contributors of decreasing 


\begin{tabular}{l|l}
\hline DOI: $10.1159 / 000477468$ & $\begin{array}{l}\text { C) 2017 S. Karger AG, Basel } \\
\text { www.karger.com/ine }\end{array}$ \\
\hline
\end{tabular}

Mehta et al.: Trends in Endovascular Treatment of Aneurysmal Subarachnoid Hemorrhages

mortality and reducing the need for angioplasty for cerebral vasospasm in patients admitted with aSAH.

\section{Disclosure Statement}

The authors of this article have no conflicts of interest to disclose. This study was done without any funding source and did not receive any financial support from anywhere.

\section{References}

1 de Rooij NK, Linn FH, van der Plas JA, Algra A, Rinkel GJ: Incidence of subarachnoid haemorrhage: a systematic review with emphasis on region, age, gender and time trends. J Neurol Neurosurg Psychiatry 2007;78:13651372.

2 Dority JS, Oldham JS: Subarachnoid hemorrhage: an update. Anesthesiol Clin 2016;34:577-600.

3 Brilstra EH, Algra A, Rinkel GJ, Tulleken CA, van Gijn J: Effectiveness of neurosurgical clip application in patients with aneurysmal subarachnoid hemorrhage. J Neurosurg 2002;97:1036-1041.

4 Brinjikji W, Lanzino G, Kallmes DF, Cloft HJ: Cerebral aneurysm treatment is beginning to shift to low volume centers. J Neurointerv Surg 2014;6:349-352.

5 Vinuela F, Duckwiler G, Mawad M: Guglielmi detachable coil embolization of acute intracranial aneurysm: perioperative anatomical and clinical outcome in 403 patients. J Neurosurg 1997;86:475-482.

6 Byrne JV, Sohn MJ, Molyneux AJ, Chir B: Five-year experience in using coil embolization for ruptured intracranial aneurysms: outcomes and incidence of late rebleeding. J Neurosurg 1999;90:656-663.

7 Raymond J, Roy D: Safety and efficacy of endovascular treatment of acutely ruptured aneurysms. Neurosurgery 1997;41:1235-1245.

8 Molyneux A, Kerr R, Stratton I, Sandercock P, Clarke M, Shrimpton J, Holman R; International Subarachnoid Aneurysm Trial (ISAT) Collaborative Group: International Subarachnoid Aneurysm Trial (ISAT) of neurosurgical clipping versus endovascular coiling in 2143 patients with ruptured intracranial aneurysms: a randomised trial. Lancet 2002;360:1267-1274.

9 Molyneux AJ, Kerr RS, Yu LM, Clarke M, Sneade M, Yarnold JA, Sandercock P; International Subarachnoid Aneurysm Trial (ISAT) Collaborative Group: International subarachnoid aneurysm trial (ISAT) of neurosurgical clipping versus endovascular coiling in 2,143 patients with ruptured intracranial aneurysms: a randomised comparison of effects on survival, dependency, seizures, rebleeding, subgroups, and aneurysm occlusion. Lancet 2005;366:809-817.

10 Koebbe CJ, Veznedaroglu E, Jabbour P, Rosenwasser RH: Endovascular management of intracranial aneurysms: current experience and future advances. Neurosurgery 2006;59(5 suppl 3):S93-S102; discussion S3S13.

11 Rincon F, Rossenwasser RH, Dumont A: The epidemiology of admissions of nontraumatic subarachnoid hemorrhage in the United States. Neurosurgery 2013;73:217-223.

12 Kale SP, Edgell RC, Alshekhlee A, Borhani Haghighi A, Sweeny J, Felton J, Kitchener J, Vora N, Bieneman BK, Cruz-Flores S, Abdulrauf S: Age-associated vasospasm in aneurysmal subarachnoid hemorrhage. J Stroke Cerebrovasc Dis 2013;22:22-27.

13 Brito da Silva H, Messina-Lopez M, Sekhar LN: Bypasses and reconstruction for complex brain aneurysms. Methodist Debakey Cardiovasc J 2014;10:224-233.

14 Adams HP Jr, Kassell NF, Torner JC, et al: Predicting cerebral ischemia after aneurysmal subarachnoid hemorrhage: influences of clinical condition, CT results, and antifibrinolytic therapy. A report of the Cooperative Aneurysm Study. Neurology 1987;37:1586-1591.

15 Haley EC Jr, Kassell NF, Torner JC, et al: A randomized trial of two doses of nicardipine in aneurysmal subarachnoid hemorrhage: a report of the Cooperative Aneurysm Study. J Neurosurg 1994;80:788-796.

16 Badjatia N, Topcuoglu MA, Pryor JC, Rabinov JD, Ogilvy CS, Carter BS, Rordorf GA: Preliminary experience with intra-arterial nicardipine as a treatment for cerebral vasospasm. AJNR Am J Neuroradiol 2004;25:819-826.

17 Biondi A, Ricciardi GK, Puybasset L, Abdennour L, Longo M, Chiras J, Van Effenterre R: Intra-arterial nimodipine for the treatment of symptomatic cerebral vasospasm after aneurysmal subarachnoid hemorrhage: preliminary results. AJNR Am J Neuroradiol 2004;25:1067-1076.

18 Feng L, Fitzsimmons BF, Young WL, Berman MF, Lin E, Aagaard BD, Duong H, Pile-Spellman J: Intraarterially administered verapamil as adjunct therapy for cerebral vasospasm: safety and 2-year experience. AJNR Am J Neuroradiol 2002;23:1284-1290. 